\title{
External Fixation in the Treatment of Displaced Midshaft Clavicle Fractures in Adults: A Retrospective Study
}

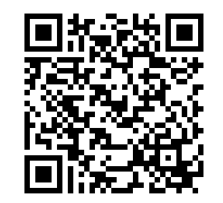

\author{
Xianzhi Ma' ${ }^{1}$, Qiyun Zhou ${ }^{1}$, Limin Liü ${ }^{2}$ Jianwu Ma $^{2}$, Shengshou Han² ${ }^{2}$ and Kai Wang2* \\ ${ }^{1}$ Trauma orthopedic Department, Xining, Qinghai Provincial People's Hospital, China
}

${ }^{2}$ Trauma orthopedic Department, Qinghai Provincial People's Hospital, Xining, China

Submission: December 14, 2019; Published: January 10, 2020

*Corresponding author: Kai Wang, Trauma orthopedic Department, Qinghai Provincial People’s Hospital, Xining, China

\begin{abstract}
The study aims to compare the clinical outcome of external fixation (EF) and plating fixation (PF) in the treatment of displaced midshaft clavicle fractures in adults. Fifty-nine patients meeting the inclusion criteria were selected; 29 cases of external fixation and 30 cases of openreduction plate fixation. The average follow-up period was 32 months. Outcomes analysis included: satisfaction with the received treatment, local appearance and shoulder function; residual symptoms; constant shoulder score (CSS); disability of the arm, shoulder and hand score (DASH). 25 cases of EF and all patients in PF group were successfully followed up. No statistically significant differences were observed between two groups in overall satisfaction ( $\mathrm{P}=0.12)$, CSS $(\mathrm{P}=0.132)$, DASH $(\mathrm{P}=0.113)$, or healing time $(\mathrm{P}=0.086)$. In the EF group, there was one case of non-union (4\%) and three cases of angular deformity. PF group had one case of non-union (3\%) and no malunion; hardware irritation and the need for a second surgery were the biggest complications. Compared with PF, EF provided a better treatment overall, with the advantages of simple procedure, no damage to the soft tissue and blood supply, a short healing time, and no second operation.
\end{abstract}

Keywords: External Fixation; Clavicle Fractures; Plating Fixation

Abbreviations: EF: External Fixation; PF: Plating Fixation; CSS: Constant Shoulder Score; DASH Disability of the Arm, Shoulder and Hand Score

\section{Introduction}

Clavicular fracture is one of the most common fractures, accounting for $5-10 \%$ of whole bone fractures. $80 \%$ of clavicular fractures occur at the midshaft, and displacement happened in over half of these cases [1-2]. In the past, midshaft clavicle fractures were often treated with conservative treatment, but recently some clinical studies reported that nonoperative treatment often leads to non-union, malunion, local pain, shoulder joint disfunction and an unpleasant appearance [3-5]. Many studies have therefore reported that operative treatments are preferable and better for treating midshaft clavicle fractures [6-9], such as external fixation (EF) and plate fixation (PF). Both treatments have advantages. The plate provides a stronger fixation and tends to be conducive to early rehabilitation exercise. An external fixator is less invasive, causes minimal damage to soft tissue, local blood supply and periosteum. The treatment is therefore effective for early bone union and local skeleton growth. The current study analyses the advantages and disadvantages of the two treatments by comparing their clinical outcomes.

\section{Materials and Methods}

This study conducted a retrospective analysis using 306 cases of patients with clavicular fractures in the trauma orthopedic department at our hospital from March 2012 to May 2015; 59 of these patients met the inclusion criteria (Table 1). Among them were 29 cases of external fixation and 30 cases of plate fixation. This study considered overall satisfaction according to satisfaction with the received treatment, local appearance and shoulder function using a 1-10 scale (1 = not satisfied at all, 10 = very satisfied). The study also considered two other outcome measures: constant shoulder score (CSS) and disability of the arm shoulder and hand score (DASH). Ethics approval was obtained from Qinghai Provincial People's Hospital Ethics Committee. Any related procedures were performed in accordance with relevant guidelines and regulations. All participants gave informed written consent. Consent for images (Figure 1) to be used in an online open-access publication was also obtained (Table 1 ). 


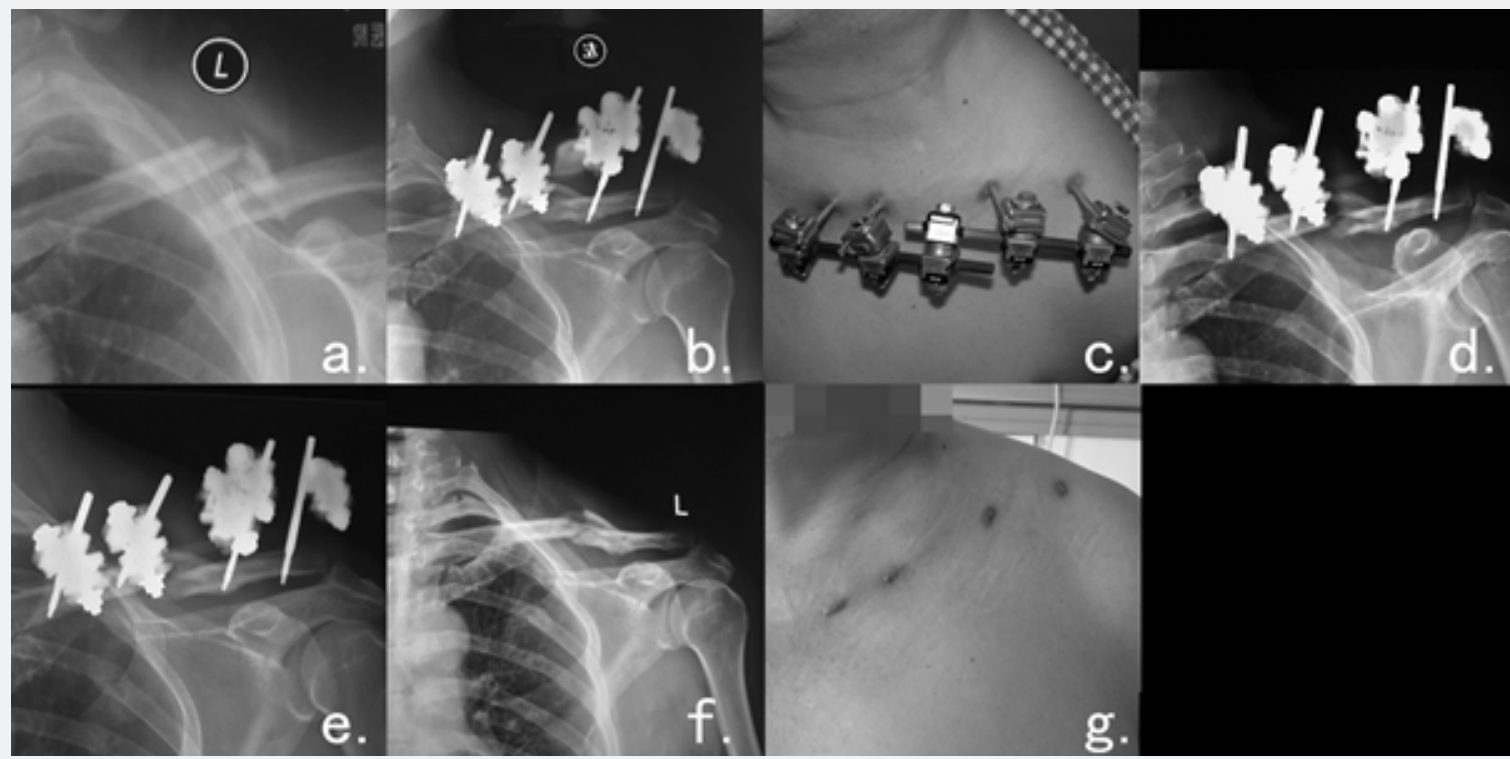

Figure 1: Typical case of external fixation.

Male patient, 57 years old, with midshaft fracture at right clavicle caused by car accident.

a. Preoperative posteroanterior radiograph of midshaft fracture of left clavicle.

b. Postoperative radiograph after external fixation.

c. The clavicle external fixator in-situ.

d. Radiograph of fracture union after 1 month.

e. Radiograph of fracture union after 2 months.

f. Radiograph of fracture union at 3-month removal of the external fixator.

g. The appearance of the shoulder is satisfactory after removal of the external fixator.

Table 1: Demographic characteristics of patients included in the retrospective study.

\begin{tabular}{|c|c|c|}
\hline & $\begin{array}{c}\text { External Fixation } \\
\text { (EF) }\end{array}$ & $\begin{array}{c}\text { Plate Fixation } \\
\text { (PF) }\end{array}$ \\
\hline Number of cases & 29 & 30 \\
\hline Male & 18 & 21 \\
\hline Female & 11 & 9 \\
\hline Average age & $42 \pm 4.2$ & $36.5 \pm 4.0$ \\
\hline Displacement more than $\mathbf{2} \mathbf{~ c m}$ & 17 & 18 \\
\hline Multiple fracture & 6 & 7 \\
\hline Soft tissue embedded & 3 & 2 \\
\hline
\end{tabular}

\section{Inclusion Criteria}

i. A 1/3 displaced midshaft clavicular fracture;

ii. Displacement at fracture site exceeding $20 \mathrm{~mm}$;

iii. Age between 14 and 60 years;

iv. No medical contraindications to general anesthesia;

v. Provided informed consent.

\section{Exclusion Criteria}

i. A fracture in the distal or proximal third of the clavicle; ii. A pathological fracture;

iii. An open fracture;

iv. No displaced fracture in the clavicle;

v. A lack of consent.

Treatments and Follow-Up

\section{External Fixation}

Under a general anesthetic, the patient was positioned in the beach-chair position. A small pad was placed behind the shoulder blade, and the physician detected the fracture site under the 


\section{Orthopedics and Rheumatology Open Access Journal (OROAJ)}

fluoroscopy and marked it using the Kirschner wire. Two selfdrilling/self-tapping pins (Stryker, APEX, 5038-1-080; diameter = $3.0 \mathrm{~mm}$, length $=80 \mathrm{~mm}$, length of thread $=10 \mathrm{~mm}$ ) were inserted on the middle part from the anterior to the posterior along a horizontal plane in a slightly cephalad direction. Two pins were inserted slantways in the supero-inferior and anterior-posterior directions on the lateral fragment. The limb was then supported in an arm pouch sling. Functional exercise was taken under guidance after operation, and after 12 weeks following the operation, the physician removed the external fixator. Follow-up was done every 4 weeks until the physician identified bone union. Figure 1 shows one typical case of external fixation.

\section{Plate Fixation}

The patient was under anesthesia and positioned in a beachchair in a semi-sitting position. The physician prepared the

\section{Results}

Table 2: Appearance of the shoulder for the two treatment groups.

\begin{tabular}{|c|c|c|}
\hline & EF & PF cases \\
\hline Asymmetry & $\mathbf{2 5 \text { cases }}$ & 0 \\
\hline Droopy Shoulder & 2 & 0 \\
\hline Scar & 0 & 2 \\
\hline Rate of Satisfaction & 0 & $28 / 30(93 \%)$ \\
\hline
\end{tabular}

Table 3: Comparisons between the three treatment groups on CSS, DASH and time of union.

\begin{tabular}{|c|c|c|c|}
\hline & EF & PF & P-value \\
\hline cases & 29 & 30 & 0.132 \\
\hline CSS Score & $94.0 \pm 6.4$ & $92.9 \pm 8.4$ & 0.113 \\
\hline DASH Score & $15.2 \pm 3.4$ & $15.7 \pm 3.5$ & 0.086 \\
\hline Time of union (weeks) & $10.4 \pm 2.3$ & $12.1 \pm 2.5$ & \\
\hline
\end{tabular}

Table 4: Complications observed in the two treatment groups.

\begin{tabular}{|c|c|c|}
\hline & EF & PF \\
cases \\
\hline Nonunion & 1 & 1 \\
\hline Malunion & 3 & 1 \\
\hline Pin Infection & 4 & 0 \\
\hline Wound Infection & 0 & 1 \\
\hline Complex Regional Pain Syndrome & 1 & 0 \\
\hline Hardware irritation & 3 & 12 \\
\hline Early Mechanical Failure & 0 & 1 \\
\hline In Total & $12 / 2548 \%$ & $16 / 3052 \%$ \\
\hline
\end{tabular}




\section{Orthopedics and Rheumatology Open Access Journal (OROAJ)}

Table 5: Comparisons of bleeding, operation time and fracture reduction for the two treatment groups.

\begin{tabular}{|c|c|c|c|}
\hline & EF & PF & P Value \\
\hline Bleeding (ml) & $13.2 \pm 3.2$ & $77.3 \pm 42.6$ & $<0.001$ \\
\hline Operation Time (min) & $49.1 \pm 8.2$ & $100.5 \pm 28.9$ & $<0.001$ \\
\hline Anatomical reduction & 7 & 29 & $<0.001$ \\
\hline Functional reduction & $22^{*}$ & 1 & \\
\hline
\end{tabular}

*Among 22 cases of functional reduction in external fixation group, there are 9 cases of $1 / 3$ reduction, 11 cases of $2 / 3$ reduction, and 2 cases of non-reduction.

On average, the study followed up in 32 months with the participants, during which four cases in the EF group were lost. The PF group had a $100 \%$ follow-up rate. There were no differences in the fracture healing time between the two groups; the EF group took $10.4 \pm 2.3$ weeks, while the PF group took $12.1 \pm 2.6$ weeks $(\mathrm{P}=0.086)$. This study observed no significant difference in overall satisfaction (EF: $5.6 \pm 3.4$ vs. PF: $6.0 \pm 2.4$; $\mathrm{P}=0.32$ ) and shoulder joint function (EF: $7.4 \pm 1.7$ vs. PF: $7.6 \pm$ 1.3; $\mathrm{P}=0.21$ ) between the two groups. For local appearance, the EF group presented higher satisfaction than the PF group (7.2 \pm 3.6 vs. $5.3 \pm 2.3 ; \mathrm{P}=0.002$ ) (Table 2 ). No statistically significant differences were observed between EF and PF in CCS and DASH (Table 3), while the EF group achieved a slightly higher CSS score than the PF group. The major complications for the EF group were pin infection and early mechanical failure. For the PF group, hardware irritation and repeat interventions were the most common (Table 4). The EF group experienced less bleeding and a shorter operation time than the PF group ( $<<0.001$, Table 5). The most significant advantage of $\mathrm{PF}$, compared to $\mathrm{EF}$, lies in its increased frequency of anatomical reduction between the fracture ends $(\mathrm{P}<0.001$, Table 5).

\section{Discussion}

As a minimally invasive technology, EF does little damage to blood supply (compared to PF) with no need for a second surgery. In contrast, PF risks injuring nerves and blood vessels during operation and poses several complications, including hardware irritation and a second operation. PF is the most used and effective treatment, considering it can reduce and fix the fracture ends under direct vision, has a higher bone union rate and better shoulder function recovery $[10,11]$. However, it also has disadvantages, including larger scars and a higher rate of implant irritation that can lead to a requirement for a second operation. It requires a general anesthetic if plates must be removed $[12,13]$. Appropriate surgical methods should therefore be selected according to clinical conditions. Good reduction and rigid fixation of the broken ends of a clavicular fracture guarantees bone union. An EF satisfactorily reduces the fracture ends by means of simple percutaneous manipulation, maintaining it until bone union.
The EF group had the lowest fracture healing time at about 11 weeks, with an impressive union rate of $96 \%$. Shukla et al. similarly reported for their 25 cases of displaced midshaft clavicular fractures that EF treatment resulted in a union rate of $92 \%[14,15]$. Through a minimally invasive operation, EF avoids damaging the blood supply and soft tissue of fracture ends while still obtaining good functional reduction between bone fracture ends. The result is a good biological and biomechanical environment for a fracture union. Indeed, in the current study EF achieved both a $96 \%$ clinical union rate and greatly shortened fracture healing time. On the other hand, PF has advantages, such as complete anatomical reduction, no fracture malunion and early functional exercise. Its healing time in the current study tended to be short and the union rate was as high as $97 \%$.

Constant shoulder scores (CSS) and the disability of the arm, shoulder and hand score (DASH) are by far the most used scoring standards for shoulder joint function after clavicular fracture treatment. In the current study, all patients received satisfactory scores, and there were no significant differences in CSS and DASH scores ( $p=0.132$ and $p=0.133$, respectively) between the two groups during the last follow-up. The two surgical methods are therefore equally effective in terms of improving the functional activities of shoulder joints.

Regarding complications, physicians loosened four pins in two cases of fractures in the EF group. Pin infection occurred in a total of eight pins across four different patients. Patients were satisfied with shoulder appearance. Prior to the remove of the EF, patients' movement of the neck and dressing were affected. Hardware irritation and secondary surgery were the most common complications in the PF group. The complication rates of the $\mathrm{EF}$ and $\mathrm{PF}$ groups were $48 \%$ and $52 \%$, respectively. According to our results and considering the amount of bleeding and operation time, the EF group fared better overall than the $P F$ group $(P=0.000)$. Regarding satisfaction of intraoperative fracture reduction, the PF group showed advantages over the EF group $(\mathrm{p}=0.000)$. There was no significant difference in other complications. 
For adults with midshaft clavicular fracture or displacement where the broken end is greater than $20 \mathrm{~mm}$ (compared to the healthy side), surgery is a reasonable option. In the current study, EF can completely replace PF. There are some clinical reports on treating such fractures with the EF, and the sample size of this study was relatively small as a retrospective study. We therefore cautiously believe that the efficacy of EF may exceed that of other treatment methods; prospective multicentre randomized clinical studies with large sample sizes are needed to further confirm the clinical efficacy of this method.

\section{Conclusion}

External fixation has significant advantages, including using a small incision, minimal damage to soft tissue and blood supply, quick bone healing and high patient satisfaction. Our results in this study and the literature lead us to believe EF is the most effective treatment for displaced midshaft clavicular fractures in adults.

\section{Acknowledgement}

We thank Ms. Junya Zhao for her assistance in language editing.

\section{Conflict of Interest}

All authors declare that they have no conflict of interest.

\section{References}

1. Postacchini F, Gumina S, De Santis P, Albo F (2002) Epidemiology of clavicle fractures. J Shoulder Elbow Surg 11(5): 452-456.

2. Nordqvist A, Petersson C (1994) The incidence of fractures of the clavicle. Clin Orthop Relat Res 300:127-132.

3. Hill JM, McGuire MH, Crosby LA (1997) Closed treatment of displaced middle-third fractures of the clavicle gives poor results. J Bone Jt Surg Br 79(4): 537-539.

4. Nowak J, Holgersson M, Larsson S (2004) Can we predict long-term sequelae after fractures of the clavicle based on initial findings? A prospective study with nine to ten years of follow-up. J Shoulder Elb Surg 13(5): 479-486.
5. McKee MD, Pedersen EM, Jones C, Stephen DJ, Kreder HJ, et al. (2006) Deficits following nonoperative treatment of displaced midshaft clavicular fractures. J Bone Jt Surg Am 88(1): 35-40.

6. Tamaoki MJS, Matsunaga FT, Costa A, Netto NA, Matsumoto MH, et al. Treatment of displaced midshaft clavicle fractures: figure-of-eight harness versus anterior plate osteosynthesis: a randomized controlled trial. J Bone Jt Surg Am 99(14): 1159-1165.

7. Woltz S, Stegeman SA, Krijnen P, van Dijkman BA, van Thiel TP, et al. (2017) Plate fixation compared with nonoperative treatment for displaced midshaft clavicular fractures:a multicenter randomized controlled trial. J Bone Jt Surg Am 99(2): 106-112.

8. Woltz S, Krijnen P, Schipper IB (2017) Plate fixation versus nonoperative treatment for displaced midshaft clavicular fractures: a meta-analysis of randomized controlled trials. J Bone Jt Surg Am 99(12): 1051-1057.

9. Ahrens PM, Garlick NI, Barber J, Tims EM; Clavicle Trial Collaborative Group (2017) Clavicle Trial Collaborative G.The clavicle trial: a multicenter randomized controlled trial comparing operative with nonoperative treatment of displaced midshaft clavicle fractures. J Bone Jt Surg Am 99(16): 1345-1354.

10. Canadian Orthopaedic Trauma Society (2007) Nonoperative treatment compared with plate fixation of displaced midshaft clavicular fractures. A multicenter, randomized clinical trial. J Bone Joint Surg Am 89(1): $1-10$.

11. Khorami M , Fakour M , Mokarrami H, et al. The Comparison of Results of Treatment of Midshaft Claicle Fracture between Operative Treatment with Plate and Non-Operative Treatment. Archives of Bone \& Joint Surgery 2(3): 210

12. Lodhi I A, Russell R, Sharp D J, Shah KY (2007) The treatment of nonunion of the clavicle with the AO mini external fixator. Surgeon 5(6): 335-338.

13. Barlow T, Upadhyay P, Barlow D (2014) External fixators in the treatment of midshaft clavicle non-unions: a systematic review. Eur J Orthop Surg Traumatol 24(2): 143-148.

14. Khorami M , Fakour M , Mokarrami H (2014) The Comparison of Results of Treatment of Midshaft Clavicle Fracture between Operative Treatment with Plate and Non-Operative Treatment. Archives of Bone \& Joint Surgery 2(3): 210-214.

15. Burnham J M, Kim D C, Kamineni S (2016) Midshaft Clavicle Fractures: A Critical Review. Orthopedics 39(5): e814-21. 


\section{Your next submission with Juniper Publishers} will reach you the below assets

- Quality Editorial service

- Swift Peer Review

- Reprints availability

- E-prints Service

- Manuscript Podcast for convenient understanding

- Global attainment for your research

- Manuscript accessibility in different formats ( Pdf, E-pub, Full Text, Audio)

- Unceasing customer service

Track the below URL for one-step submission https://juniperpublishers.com/online-submission.php 